\title{
Psychological Empowerment: Issues and Illustrations ${ }^{1}$
}

\author{
Marc A. Zimmerman ${ }^{2}$ \\ University of Michigan
}

\begin{abstract}
Discussed several issues related to psychological empowerment. The thesis of this paper is that the development of a universal and global measure of psychological empowerment may not be a feasible or appropriate goal. I begin by distinguishing between empowerment processes and outcomes. Underlying assumptions are discussed including the notion that empowerment differs across people, contexts, and times. A nomological network that includes intrapersonal, interactional, and behavioral components is also presented. Two examples of psychological empowerment for voluntary service organization members and members of a mutual help organization are described to help illustrate differences in the specific variables that may be used to measure psychological empowerment in different populations and settings.
\end{abstract}

KEY WORDS: empowerment theory; measurement; psychological empowerment.

Empowerment is a process by which people, organizations, and communities gain mastery over issues of concern to them (Rappaport, 1987). It is a multilevel construct in which each level of analysis is interdependent with the others. Psychological empowerment (PE) refers to empowerment at the individual level of analysis (Zimmerman, 1990a). The construct integrates perceptions of personal control, a proactive approach to life, and a critical understanding of the sociopolitical environment. Zimmerman (in press) suggests that organizational empowerment includes

${ }^{1}$ I thank Deborah A. Salem for her thoughtful comments on earlier drafts of this paper and for her persistence in pushing me to strengthen the ideas presented. I also thank Douglas Perkins, Julian Rappaport, David Altman, and James G. Kelly for their very helpful comments. They helped me articulate my ideas more carefully and clearly.

${ }^{2}$ All correspondence should be sent to Marc A. Zimmerman, Department of Health Behavior and Health Education, School of Public Health, University of Michigan, Ann Arbor, Michigan 48109-2029. 
processes and structures that enhance members' skills and provide them with the mutual support necessary to effect community level change (i.e., empowering organization). He also points out that it refers to improved organizational effectiveness by effectively competing for resources, networking with other organizations, or expanding its influence (i.e., empowered organization). At the community level of analysis, empowerment refers to individuals working together in an organized fashion to improve their collective lives and linkages among community organizations and agencies that help maintain that quality of life (Zimmerman, in press).

The focus of this paper is on psychological empowerment (PE). ${ }^{3}$ The conceptual development of PE further develops empowerment theory by explicitly defining a fundamental element necessary for understanding the other levels of analysis. PE may be distinguished from organizational or community empowerment, but it also influences and is influenced by empowerment at other levels of analysis (Zimmerman, in press). The conceptualization of $\mathrm{PE}$ that is presented is rooted firmly in a social action framework that includes community change, capacity building, and collectivity (Keiffer, 1984; Rappaport, 1981; Zimmerman, in press). Social change, however, may take many forms and may not necessarily result in a power struggle.

An emphasis on empowerment at the individual level of analysis should not be taken to mean that sociopolitical or contextual factors are overlooked. PE is not simply self-perceptions of competence but includes active engagement in one's community and an understanding of one's sociopolitical environment. PE also includes learning about controlling agents and acting to influence those agents (Zimmerman, Israel, Schulz, \& Checkoway, 1992). Thus, PE should not be interpreted as individualism, the promotion of one ideology versus another, or merely an intrapsychic phenomenon. Rather, PE includes beliefs that goals can be achieved, awareness about resources and factors that hinder or enhance one's efforts to achieve those goals, and efforts to fulfill the goals.

The purpose of this paper is to provide an initial attempt at describing the nomological network (Cronbach \& Meehl, 1955) of empowerment at the individual level of analysis - psychological empowerment. A nomological network is a theoretical framework that specifies relationships among

\footnotetext{
${ }^{3}$ The term psychological empowerment is used to refer to empowerment at the individual level of analysis because it is intended to reflect a broader interpretation of the construct than simply intrapersonal characteristics (the term psychology refers to the study of both mind and behavior). Conversely, the term individual empowerment may be interpreted more narrowly as a construct that includes only what goes on in the mind. See Zimmerman (1990a) for an elaboration of this issue.
} 
variables in such a way as to help both differentiate and define the construct of concern, and that enables the formulation of a measurement model. The measurement of psychological empowerment may be especially difficult because (a) PE manifests itself in different perceptions, skills, and behaviors across people; (b) different beliefs, competencies, and actions may be required to master various settings; and (c) PE may fluctuate over time. Each of these qualities suggests that PE may be an open-ended construct that is not easily reduced to a universal set of operational rules and definitions. Thus, the development of context and population-specific measures of PE is challenging, but relevant measures can help us further develop empowerment theory, study how it changes over time, learn more about how settings may be empowering or disempowering, and evaluate interventions designed to enhance individuals' control over their lives. Nevertheless, we may have to accept the fact that the measures we develop for one study may not be appropriate for another.

\section{EMPOWERING PROCESSES VERSUS EMPOWERED OUTCOMES}

It is useful to distinguish between empowering processes and empowered outcomes because the former refers to how people, organizations, and communities become empowered, whereas the latter refers to the consequences of those processes.

\section{Empowering Processes}

Empowering processes are those where people create or are given opportunities to control their own destiny and influence the decisions that affect their lives. They are a series of experiences in which individuals learn to see a closer correspondence between their goals and a sense of how to achieve them, gain greater access to and control over resources, and where people, organizations, and communities gain mastery over their lives (Cornell Empowerment Group, 1989; Mechanic, 1991; Zimmerman, 1990a). Efforts to gain control, access to resources, and a critical understanding of one's sociopolitical context are fundamental aspects of empowering processes. Maton and Salem (1995) describe three examples of empowering settings that provide opportunities for shared leadership, development of a group identity, skill development and participation in important organizational tasks. 
When professionals are working to enhance empowered outcomes of others, an empowering process means (a) involving community members in the development, implementation, and evaluation of interventions; (b) developing an "eco-identity (Kelly, 1971, p. 899) whereby professionals become members of the community to some extent; (c) working with community members as coequal partners; and (d) creating opportunities for community members to develop skills so that they do not have to be dependent on professionals. Empowering processes might include opportunities to develop and practice skills, to learn about resource development and management, to work with others on a common goal, to expand one's social support network, and to develop leadership skills. It is essential to point out, however, that empowering processes may occur at all levels of analysis. Empowering individuals might include mentors who help adolescents learn about adult roles. Empowering organizations might include mutual help groups that help members learn organizational and leadership skills. Empowering communities might include organizational coalitions that enable citizens to have a voice in local policy decisions.

Others have written about participatory processes that are essentially empowering. Kelly (1988), for example, described several steps to help community members assume an active role in programs affecting their lives including involvement in defining the problem, developing a relevant program, implementing the program, and evaluating its process and outcomes. He termed this a participative ownership process.

Participatory action research (PAR) is another approach that exemplifies empowering processes (Brown, 1993; Chesler, 1991; Elden \& Chisolm, 1993; Hall, 1992; Rappaport, 1990; Whyte, 1991; Yeich \& Levine, 1992). In this approach, community participants become coequals in program development and evaluation. PAR provides an opportunity for community members to work together to solve problems, develop skills, become critically aware of their sociopolitical environment, and create mutual support systems. One goal of PAR is to help communities develop the knowledge they need to improve their quality of life and influence relevant policy. In some instances, a consciousness-raising experience may need to take place before participants can begin to be empowered. PAR is also a vehicle to create social change while helping to build competent communities (Cottrell, 1983; Iscoe, 1974) and, thereby, enhance community empowerment. Participatory action research is not only an example of an empowering process, it also provides a mechanism for developing outcome measures that are relevant and appropriate for a given context and population. 
Empowering processes may result in both empowered outcomes and other desired health outcomes. Zimmerman, Ramirez, Suarez, de la Rosa, and Castro (1994), for example, found that an empowering intervention designed to provide Mexican homosexual men with ownership and control over the development, implementation, and evaluation of an AIDS prevention program resulted in safer sexual practices among participants, as compared to individuals who did not participate in the program. They did not, however, assess empowered outcomes. This project illustrates how empowered outcomes may not be the only consequence of empowering interventions.

\section{Empowered Outcomes}

Empowered outcomes refer to specific measurement operations (whether they are quantitative or qualitative in nature) that may be used to study the effects of interventions designed to empower participants, investigate empowering processes and mechanisms, and generate a body of empirical literature that will help develop empowerment theory. Empowered outcomes are one consequence of empowering processes.

The primary issue for empowered outcomes is the development of locally relevant measures. How do we know an empowered outcome when we see it? First, a conceptual definition of empowerment that is consistent with the empirical literature helps delineate the boundaries of the construct. The conceptualizations differ across levels of analysis, but the themes of mastery and control, resource mobilization, and sociopolitical context and participation would be expected to be part of the definition in some form at each level, because research on empowerment has consistently found these variables to be central to the construct. The context and populationspecific characteristic of $\mathrm{PE}$ means that a nomological network must be broad enough to encompass diversity, yet specific enough to inform assessment of the construct for a particular population and setting. The remainder of this paper elaborates upon a conceptual framework for empowered outcomes at the individual level of analysis (i.e., psychological empowerment).

\section{UNDERLYING ASSUMPTIONS}

Three underlying assumptions of $\mathrm{PE}$ are presented to help set the framework for a more specific discussion of the nomological network of PE. The first assumption is that PE takes different forms for different people (Rappaport, 1984; Zimmerman, 1990a). Populations may be differentiated in various ways (e.g., age, socioeconomic status, sex) and the 
distinguishing characteristics one chooses may influence the meaning of PE for one's research. We should not, for example, expect a pregnant teenager to require the same perceptions, skills, or actions for increasing her sense of empowerment as an unemployed factory worker. The pregnant teen may need to develop the confidence, support, and behavioral strategies to be a good parent, while also completing school, whereas the unemployed worker may need to develop the motivation for retraining, acquire new skills, and find opportunities to practice those skills.

Second, empowerment takes different forms in different contexts. An organization with a hierarchical structure may require different skills, knowledge, and actions for workers to develop control and influence in that setting than the skills, knowledge or action required in an organization that has a more participatory structure. Empowered individuals in an authoritarian organization may need to use collective action or learn how to circumvent official channels of communication, while competency in group problem-solving and decision-making skills may be more relevant for individuals in a more participatory organization. Conversely, a vertical structure in a mutual help organization may more likely be developed by the membership through a participatory process, as a way to provide leadership opportunities for individuals who are typically left out of such roles in other aspects of their lives. The leadership in this type of organization may be more concerned with performing administrative chores than with maintaining a chain of command and accountability.

This contextual determinism also suggests that PE may vary across different life domains (e.g., work, family, recreation). A high level of empowerment might be expected among individuals who can generalize skills across life domains, but some individuals may also experience PE in one life domain even if they have been less successful in transferring skills to other life domains. An assembly line worker, for example, may feel alienated at work, but feel quite empowered as the deaconess of her church.

The third assumption is that $\mathrm{PE}$ is a dynamic variable that may fluctuate over time. PE is not a static trait; rather, it changes over time. This suggests that every individual has the potential to experience empowering and disempowering processes, and to develop a sense of empowerment at one time and disempowerment at another. It also suggests that people may become more empowered over time. Some people may develop a sense of empowerment through direct efforts to exert control; others may do so because they have access to resources for exerting control over their environment. The changing nature of PE also suggests that some individuals may be more or less empowered than other individuals. Similarly, when the context of empowerment changes over time, so too may the indicators of empowered outcomes in that context. 
These characteristics of PE make it unlikely that a universal measure of empowerment would fit all (or most) persons, or that a global measure would fit all (or most) contexts. A universal and global measure of PE may not be appropriate, because it is theoretically inconsistent with the construct given the specific demands and characteristics of different settings and life situations. A universal global measure may also confuse our understanding of PE because the construct may be inappropriately conceptualized as a static personality trait instead of a more dynamic contextually driven construct. This translates into a most important conclusion for empowerment theory: The development of a universal and global measure of empowerment is not an appropriate goal because it may not mean the same thing for every person, organization, or community everywhere.

\section{NOMOLOGICAL NETWORK FOR PSYCHOLOGICAL EMPOWERMENT}

Cronbach and Meehl (1955) described a process for construct validation that is theoretically driven and empirically tested. They suggest that a construct is, by definition, open-ended and requires the specification of interrelationships among observable phenomena that represent abstract concepts. They referred to this interlocking system of relationships as a nomological network that can be tested empirically once concrete operations for the constructs in the network are specified. The open-ended nature of many psychological constructs (e.g., mental competency to stand trial; Roesch \& Golding, 1980), however, implies that the facts and rules used to represent a construct may change over time and depend upon the context in which it is measured. Roesch and Golding (1980) suggested that "to infer competency is to engage in a complex process of judgement that is situationally dependent upon the facts of the instant case, but is not completely reducible to a set of rules about those facts" (p. 13). Thus, open-ended constructs may include observational terms and rules, but may not be fully captured by any one specific operationalization because they take on different forms in different population, contexts, and times. PE may, therefore, be considered an open-ended construct, because it too depends upon context, population, and developmental period. A necessary first step in the process of identifying observable measures relevant to PE, or any open-ended construct, is to describe a general framework to represent some fundamental aspects of its nomological network. 


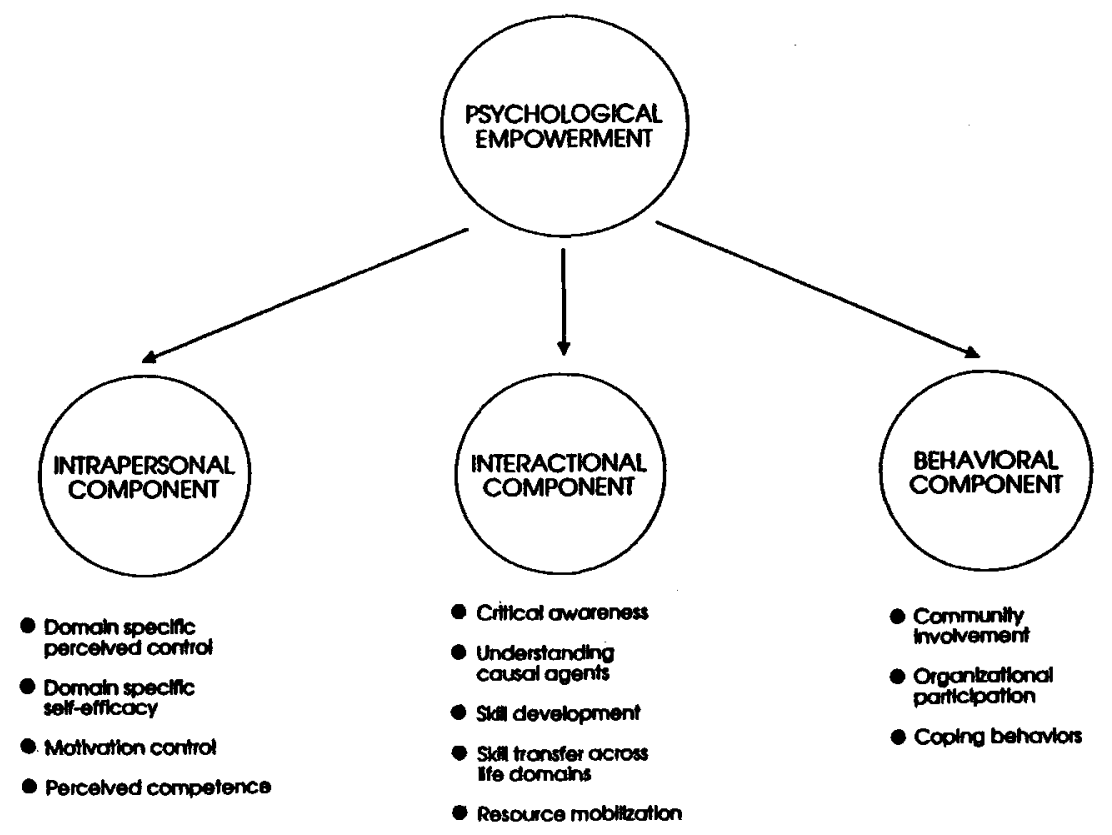

Fig. 1. Nomological network for psychological empowerment.

Several investigators have found associations among perceived control variables, skill development, and measures of participation and community involvement (Balcazar, Seekins, Fawcett, \& Hopkins, 1990; Carr, Dixon, \& Ogles, 1976; Chavis \& Wandersman, 1990; Denney, 1979; Florin \& Wandersman, 1984; Kieffer, 1984; Stone \& Levine, 1985; Zimmerman \& Rappaport, 1988; Zimmerman, et al., 1992). These constructs are all consistent with empowerment theory. As this research evidence suggests, $\mathrm{PE}$ is expected to include a sense of and motivation to control; decisionmaking and problem-solving skills and a critical awareness of one's sociopolitical environment; and participatory behaviors. Figure 1 presents these qualities of $\mathrm{PE}$ as intrapersonal, interactional, and behavioral components.

Intrapersonal Component. The intrapersonal component refers to how people think about themselves and includes domain-specific perceived control and self-efficacy, motivation to control, perceived competence, and mastery. Domain-specific perceived control refers to beliefs about one's ability to exert influence in different life spheres such as in family, work, or sociopolitical contexts (Paulhus, 1983). As Figure 1 indicates, the intrapersonal component of 
PE includes perceived control, competence, and efficacy. The intrapersonal component includes perceptions because they are a basic element that provides people with the initiative to engage in behaviors to influence desired outcomes (Strecher, DeVellis, Becker, \& Rosenstock, 1986). It is unlikely that individuals who do not believe that they have the capability to achieve goals would either learn about what it takes to achieve those goals, or do what it takes to accomplish them. Intrapersonal variables that are not presented in Figure 1, but are expected to correlate negatively with $\mathrm{PE}$, include perceptions of social isolation, powerlessness, and normlessness (Zimmerman \& Rappaport, 1988; Zimmerman, 1990b), and helplessness (Rappaport, 1984).

Interactional Component. The interactional component of $\mathrm{PE}$ refers to the understanding people have about their community and related sociopolitical issues. This aspect of PE suggests that people are aware of behavioral options or choices to act as they believe appropriate to achieve goals they set for themselves (Zimmerman, 1990a). Individuals must learn about their options in a given context in order to be able to exert control in their environment. This suggests that they need to understand the norms and values of a particular context. Relevant norms and values might include cooperative decision making, commitment to collective (versus personal) interests, or mutual assistance. Individuals may also need to develop a critical awareness of their environment, including an understanding of causal agents in order to effectively interact in the settings that are important to them. Critical awareness refers to one's understanding of the resources needed to achieve a desired goal, knowledge of how to acquire those resources, and skills for managing resources once they are obtained (Kieffer, 1984; Freire, 1973). This ability to mobilize resources is an essential aspect of the interactional component of PE because it suggests environmental mastery. Understanding causal agents refers to an appreciation of the factors that may influence those people (e.g., mayor, landlord), objects (e.g., toxic chemical, organizational structure), or events (e.g., natural disaster, public hearing) seen to either inhibit or enhance one's efforts to exert control in the sociopolitical environment (Sue \& Zane, 1980). The interactional component of empowerment also includes decision-making problem-solving, and leadership skills. These skills may be developed in settings where participants have opportunities to become involved in decision making, or inhibited in settings where participation is not an option. It is these skills that help individuals become independent, enable them to control events in their lives, and lead them to become their own best advocates. Thus, the interactional component provides the bridge between perceived control and taking action to exert control. Although the interactional component includes both cognitive understanding and learning about one's environment, these may be considered preparatory to participation because they are indirectly linked to the behaviors needed to influence outcomes. 
Behavioral Component. The behavioral component of PE refers to actions taken to directly influence outcomes. Empowerment behaviors for patients just released from a psychiatric institution, for example, might include getting involved with a mutual help group, seeking employment, and living independently. Empowerment behaviors for a young adolescent beginning high school might be playing on an athletic team, working on a student newspaper, or joining a student association (e.g., forensic team, drama club). The behavioral component may also include behaviors to manage stress or adapt to change.

These three components of PE merge to form a picture of a person who believes that he or she has the capability to influence a given context (intrapersonal component) understands how the system works in that context (interactional component), and engages in behaviors to exert control in the context (behavioral component). One implication of this nomological network is that if only information about intrapersonal characteristics is collected then a complete picture of PE cannot be made. All three components must be measured to fully capture PE. They must also include measures that are appropriate for the population and context under study.

Further development of empowerment theory needs to examine how the intrapersonal, interactional, and behavioral components interact to form PE. How do these three components relate to one another? Are some components of PE contingent upon others? It is noteworthy that the nomological network presented refers to the individual level of analysis and, therefore, reflects individual level variables. Organizational or community empowerment outcomes would necessarily require organizational or community level variables (see Zimmerman, in press).

\section{DISTINCTIONS FROM OTHER PSYCHOLOGICAL CONCEPTS}

Distinguishing PE from other psychological constructs may help to more clearly delineate its nomological network. Self-efficacy, self-esteem, competence and mental health, and power are particularly relevant concepts because they may appear to be similar constructs. Other constructs may also be comparable, but only these are briefly discussed below. The nomological network of PE includes self-efficacy, but perceptions about ability to influence outcomes is only one part of the intrapersonal component of PE. Zimmerman and Rappaport (1988) found that the combined variance of 11 different measures of perceived control formed a single dimension (i.e., canonical variate) that distinguished individuals with varying levels of involvement in community organizations 
and activities. The 11 perceived control measures included general self-efficacy, political efficacy, locus of control, and motivation to control. The single dimension formed by the perceived control measures could be considered to represent the intrapersonal component of PE in this population, because it correlated as hypothesized with measures of the behavioral component. This study suggests that self-efficacy was only one part of the intrapersonal component. Zimmerman et al. (1992) also found that self-efficacy variables were only one part of the intrapersonal component of empowerment among 911 randomly selected suburban and urban adults.

Self-esteem refers to individuals' personal judgement of their own worth (Coopersmith, 1967), but does not necessarily include perceptions about one's perceived control, participatory behavior, critical awareness, or specific skills necessary to exert control in a particular setting. Selfesteem is typically considered a personality trait, although it may result from an evaluation of one's environment and may also be domain specific (Harter, 1990). It is, however, largely an intrapersonal construct because it primarily refers to individual perceptions of oneself. Self-esteem is expected to be related positively to PE, but individuals with low self-esteem may demonstrate some characteristics of a psychologically empowered person. Persons with low self-esteem, for example, may report involvement in community activities or organizations and indicate a critical awareness of their community. They may have an illusion of incompetence (Langer, 1979) even though they have many other characteristics associated with PE.

Another concept that is related to $\mathrm{PE}$, but may be distinguished from it, is the construct of competence. Competence does not typically include sociopolitical factors; so issues such as political awareness, causal agents, and social change are not specifically connected to the construct. Similarly, competence usually does not include organized action or working with others to influence social change. Thus, although competence may also include intrapersonal, interactional, and behavioral components, the content of each of these aspects of the construct would be quite different than they would be for PE. Competence also tends to be connected to reactions to environmental events (e.g., coping with adversity), whereas PE tends to be linked to proactive behavior. Nevertheless, perceived competence may be one aspect of the intrapersonal component of PE for some populations and contexts.

Similarly, mental health is related to but distinct from PE. The concept of mental health can be conceptualized as either the absence of mental illness or the presence of healthy behavior and cognition. PE grows out of the latter approach to mental health, however, it is possible for a mentally 
distressed individual to be somewhat empowered. Individuals experiencing a severe mental illness may be empowered if they try to gain control in their lives by becoming involved in a mutual help group, developing effective coping skills, or achieving a critical understanding of how the medical establishment functions to treat their illness. Rappaport, Reischl, and Zimmerman (1991) described four case examples of how former psychiatric patients may develop different levels of PE. One case described how being helped by others suffering from similar problems resulted in some level of empowerment. A second case described how the process of helping others was empowering for the helpers. The third and fourth cases provided examples of members of the organization taking small and large leadership roles in the organization. Fairweather's lodge program provides another example of how people with serious mental illness, living and working in cooperative groups in the community, may have become empowered (Fairweather, Sanders, \& Tornatzky, 1969). They developed a member-controlled, self-sustaining living and working community.

PE also different from but related to power. Power suggests authority, whereas PE is a feeling of control, a critical awareness of one's environment, and an active engagement in it. One can be psychologically empowered without having the ultimate authority or power to realize one's objectives. Individuals do not require the possession of authoritative power in order to take action to exert control over those who do have such power. Several instances of people with low social status and no official authority struggling to influence social policy and succeeding have been reported (Checkoway \& Doyle, 1980; Fish, 1973; O'Sullivan, Waugh, \& Espeland, 1984; Piven \& Cloward, 1977). In each instance, politically disenfranchised groups successfully exerted control over people in positions of governmentally mandated power. They did not actually gain any authoritative power (except in the case of Checkoway \& Doyle, 1980), but they probably did become somewhat empowered because they may have gained confidence in their ability to influence outcomes, learned about causal agents and resources needed to effect change, and worked together to implement social change.

Gruber and Trickett (1987) raised an interesting paradox about the relationship between power and empowerment. They described an example where students and parents were given an opportunity to participate in the decision-making process of an alternative public school. They found that although the parents and students developed some amount of PE, the school authorities maintained their grasp on the final power to make changes in school policy. Thus, the individuals felt empowered, but they did not obtain real power to exert control in this context. It could be argued that because the parents and students did not have actual control they were 
not really empowered. This, however, might be an erruneous conclusion for several reasons. First, the experience of working to influence school policy may have helped them develop the confidence that they could influence school policy. The intrapersonal component of empowerment may have been enhanced. Second, the parents and students may have learned about the resources, constraints, and inner workings of the school system. This suggests some amount of empowerment as it relates to the interactional component. Third, the parents and students may have organized others to monitor the actions of school officials or to elect a slate of candidates for the school board (behavioral component).

Actual power or control is not necessary for empowerment because in some contexts and for some populations real control or power may not be the desired goal. Rather, goals such as being more informed, more skilled, more healthy, or more involved in decision making may be the desired outcome. Thus, actual power or control in a particular domain may be a sufficient condition for PE, but not a necessary one.

\section{SETTING SPECIFIC EXAMPLES OF PSYCHOLOGICAL EMPOWERMENT}

The operationalization of PE for members of a voluntary service organization and mutual help group are presented to illustrate how the nomological network of PE may be applied. ${ }^{4}$ Voluntary organizations are used as examples because several researchers have identified such settings as vital to the development of PE (Prestby, Wandersman, Florin, Rich, \& Chavis, 1990; Rappaport, 1981; Rich, Edelstein, Hallman, \& Wandersman, 1995; Zimmerman et al., 1992; Zimmerman \& Rappaport, 1988). Two similar types of organizations are chosen to help illustrate the relevance of context for defining PE even in comparable settings. The organizations, though similar, may differ in significant ways. They may have different goals, benefits, and functions for members. In addition, members may have different motivations for choosing to participate in each type of organization. Thus, PE for members of a voluntary service organization may be quite different than PE for members of a mutual help organization.

\footnotetext{
${ }^{4} \mathrm{~A}$ voluntary service organization is one which the primary goal is to provide some benefits to the community. Services provided might include fund raising for Little League Baseball, neighborhood crime watch, volunteer help in a local hospice, or provision of unique opportunities for community members to have access to media outlets. Organizational examples include neighborhood associations, Kiwanis Club, and community radio stations. These types of organizations are distinguished from organizations whose primary goal is to provide benefits to individual members such as mutual help groups or hobby clubs.
} 


\section{Voluntary Service Organization Members}

The specific measures associated with each component of the nomological network of PE for members of voluntary community service organizations parallels the more general indicators depicted in Figure 1. PE in voluntary service organizations might include sociopolitical control, leadership in the organization, and an understanding of the resources needed to manage a fund-raising campaign. Sociopolitical concerns may be most relevant for the intrapersonal component for this population because the context includes community settings that may be involved in resource development (e.g., fund raising), policy issues, or service provision. The intrapersonal component might include three aspects of perceived control: sociopolitical control; perceived competence in the sociopolitical domain; and desire to exert control in the public arena (i.e., motivation).

The interactional component might include a critical understanding of the sociopolitical environment and the cultivation of personal and collective resources for political action (Kieffer, 1984), as well as development of skills and knowledge (Prestby et al., 1990). Members of voluntary organizations may develop decision-making skills, learn how to critically assess resources, and learn about the factors that influence causal agents when they work on a fund-raising project, design a new service project, or help maintain the organization. Leadership skills may include organizing others to achieve a common goal and speaking in front of large groups.

The behavioral component of PE for voluntary service organization members might include participation in community activities and level of involvement in voluntary organizations (Zimmerman \& Rappaport, 1988). Community activities expected to be related to $\mathrm{PE}$ in this context might include voting, writing letters to an editor or elected official, helping to organize neighborhood health fairs, or taking part in neighborhood crime watch activities. Level of involvement in a voluntary organization might refer to attendance at organizational meetings, leadership positions held, length of time involved, and average number of hours volunteered on a monthly basis.

The resulting multidimensional measure might include a paper-andpencil scale found in the research literature to assess the intrapersonal component. Zimmerman and Zahniser (1991) reported the development of a sociopolitical control scale that might be especially useful for measuring this component of PE for members of a voluntary organization. The scale, developed from 10 of the measures used by Zimmerman and Rappaport (1988), includes leadership confidence and policy control subscales, and has adequate psychometric properties in three samples from different voluntary organizations. 
The measure for the interactional component could include items questioning respondents about where or how to obtain resources needed to achieve different goals (e.g., increase membership, raise funds). A score on this measure could be developed that weights effective response options. Data from organizational records could be used to measure the behavioral component by examining attendance at meetings and length of time involved in the organization. Self-report items regarding one's leadership roles, number of hours volunteered each month, and the length of time one has been involved in the organization could also be collected for measuring the behavioral component (Perkins, Florin, Rich, Wandersman, \& Chavis 1990; Zimmerman et al., 1992; Zimmerman \& Rappaport, 1988).

A total scale score could be developed by standardizing and summing across the measures for each component. Separate analyses for each component could be conducted to explore the relative effect an empowering intervention may have on each one. Multivariate analyses could be used to explore the common and unique variance of each component. Total scores could be used to evaluate the effects of empowering interventions or to explore a mediating model where empowering processes lead to empowered outcomes, which in turn, lead to health behavior.

Of course, a qualitative measurement approach may also be used that follows the same theoretical framework for defining what type of information to collect. This approach might include in-depth case studies, observations, open-ended interviews, or opportunities for individuals to tell their own story. Kieffer (1984) provided an example of a qualitative approach for assessing PE.

\section{Mutual Help Group Members}

Members of a mutual help organization, whose primary goal is to provide members with a supportive social network, would be expected to have different variables representing the three components of PE than those used for members of a voluntary service organization. Members of mutual help organizations are often trying to cope with a particular issue (e.g., chronic illness, bereavement, drug use) and may become involved with the organization in an effort to gain personal control.

Potential variables for the intrapersonal, interactional, and behavioral components of $\mathrm{PE}$ in a mutual help organization for individuals with chronic mental illness, differ from those used for members of voluntary service organizations. The intrapersonal component for mutual help group members, for example, may not include sociopolitical control; rather it may include personal control, interpersonal control, and perceived competence 
for coping. Problem-solving and coping skills may constitute the interactional component of PE for members of a mutual help group, rather than management of organizational resources and understanding of causal agents. Behaviors related to PE for mutual help group members may include taking on leadership roles, reaching out to other members of the group (i.e., 12-step work), and getting involved in other group or community activities.

The nomological network for these two populations illustrate the importance of considering context for measuring $\mathrm{PE}$, but taken together they also illustrate the developmental nature of the construct. A developmental progression for mutual help members may be to first gain the courage to participate in the group and then begin slowly to develop personal control and skills. As individuals become more involved in the group and cope effectively, they may develop skills that will allow them to become leaders in the organization. As we explore how the three components of PE interact, influence, and build upon one another, we may also begin to understand developmental processes of PE for various populations and contexts.

\section{CONCLUSION}

One of the most important messages of this paper is that psychological empowerment is more than simply an intrapersonal construct, and requires assessment of behavioral and interactional factors to thoroughly measure this open-ended construct. A universal and global measure of PE may not be desirable because it is theoretically inconsistent with the construct given the specific demands and characteristics of different settings and life situations. A universal and global measure may also confuse our understanding of empowerment because the construct may be inappropriately conceptualized as a static personality trait instead of a more dynamic contextually driven construct. The measurement of $\mathrm{PE}$ in a specific setting for a particular sample of individuals is possible, but it must be connected to the experience of the research participants as they state it, and contextually grounded in their life experiences. This approach necessarily limits one's generalizability to other persons or contexts, but we may have to accept this trade-off in order to adequately and appropriately measure PE. McGrath (1982) pointed out that all research endeavors must inevitably make trade-offs between the competing demands of external and internal validity. Research on empowerment theory is not unique in this regard and, as McGrath suggested, the development of any theory requires programmatic research that builds a body of knowledge. The ideas presented in this paper are intended to help point us in that direction. 


\section{REFERENCES}

Balcazar, F. E., Seekins, T., Fawcett, S. B., \& Hopkins, B. L., (1990). Empowering people with physical disabilities through advocacy skills training. American Joumal of Community Psychology, 18, 281-296.

Brown, L. D. (1993). Social change through collective reflection with Asian nongovernmental development organizations. Human Relations, 46, 249-273.

Carr, T. H., Dixon, M. C., \& Ogles, R. M. (1976). Perceptions of community life which distinguish between participants and nonparticipants in a neighborhood self-help organization. American Journal of Community Psychology, 4, 357-366.

Chavis, D. M., \& Wandersman, A. (1990). Sense of community in the urban environment: A catalyst for participation and community development. American Journal of Community Psychology, 18, 55-81.

Checkoway, B., \& Doyle, M. (1980). Community organizing lessons for health care consumers. Journal of Health Politics, Policy, and Law, 5, 213-226.

Chesler, M. A. (1991). Participatory action research with self-help groups: An alternative paradigm for inquiry and action. American Journal of Community Psychology, 19, 757-768.

Coopersmith, S. (1967). The antecedents of self-esteem. San Francisco: Freeman.

Cornell Empowerment Group. (1989). Empowerment and family support. Networking Bulletin, $1,1-23$.

Cottrell, L. S., Jr. (1983). The competent community. In R. Warren \& L. Lyon (Eds.), New perspectives on the American community (pp. 398-432). Homewood, IL: Dorsey.

Cronbach, L. J., \& Meehl, P. E. (1955). Construct validity in psychological tests. Psychological Bulletin, 52, 281-302.

Denney, W. M. (1979). Participant citizenship in a marginal group: Union membership of California farm workers. American Journal of Political Science, 23, 330-337.

Elden, M., \& Chisolm, R. F. (Eds.). (1993). Emerging varieties of action research: Introduction to the special issue. Human Relations, 46, 121-142.

Fairweather, G. W., Sanders, D. H., \& Tornatzky, L. G. (1969). Community life for the mentally ill: An alternative to alternate care. Chicago, IL: Aldine.

Fish, J. (1973). Black power/white control: The struggle of the Woodlawn Organization in Chicago. Princeton, NJ: Princeton University Press.

Florin, P., \& Wandersman, A. (1984). Cognitive social learning and participation in community development. American Journal of Community Psychology, 12, 689-708.

Freire, P. (1973). Education for critical consciousness. New York: Seabury.

Gruber, J., \& Trickett, E. J. (1987). Can we empower others? The paradox of empowerment in the governing of an alternative public school. American Journal of Community Psychology, 15, 353-371.

Hall, R. H. (Ed.). (1992). Participatory research, Part I. American Sociologist, 23 (Whole issue).

Harter, S. (1990). Causes, correlates, and the functional role of global self-worth: A life-span perspective. In R. J. Sternberg \& J. Kolligan, Jr. (Eds.), Competence considered (pp. 67-97). New Haven, CT: Yale University Press.

Iscoe, I. (1974). Community Psychology and the competent community. American Psychologist, 29, 607-613.

Kelly, J. G. (1971). Qualities for the community psychologist. American Psychologist, 26, $897-903$.

Kelly, J. G. (1988). A guide to conducting prevention research in the community: First steps. Prevention in Human Services, 6, 1-174.

Kieffer, C. H. (1984). Citizen empowerment: A developmental perspective. Prevention in Human Senvices, 3, 9-36.

Langer, E. J. (1979). The illusion of incompetence. In L. V. Perlmutter \& R. A. Monty (Eds.), Choice and perceived control (pp. 301-313). Hillsdale, NJ: Erlbaum.

Maton, K. E., \& Salem, D. A. (1995). Organizational characteristics of empowering community settings: A multiple case study approach. American Joumal of Communily Psychology, 23, 
McGrath, J. E. (1982). Dilemmatics: The study of research choices and dilemmas. In J. E. McGrath, J. Martin, \& R. A. Kulka (Eds.). Judgment calls in research (pp. 69-102). Beverly Hills: Sage.

Mechanic, D. (1991, February). Adolescents at risk: New directions. Paper presented at the annual Conference on Health Policy, Cornell University Medical College.

O'Sullivan, M. J., Waugh, N., \& Espeland, W. (1984). The Fort McDowell Yavapai: From pawns to powerbrokers. Prevention in Human Services, 3, 73-97.

Paulhus, D. (1983). Sphere-specific measures of perceived control. Journal of Personality and Social Psychology, 44, 1253-1265.

Perkins, D. D., Florin, P., Rich, R. C., Wandersman, A., \& Chavis, D. M. (1990). Participation and the social and physical environment of residential blocks: Crime and community context. American Journal of Community Psychology, 18, 83-116.

Piven, F. F., \& Cloward, R. A. (1977). Poor people's movements: Why they succeed, how they fail. New YorK Vintage.

Prestby, J. E., Wandersman, A., Florin, P., Rich, R., \& Chavis, D. M. (1990). Benefits, costs, incentive management, and participation in voluntary organizations: A means to understanding and promoting empowerment. American Journal of Community Psychology, $18,117-149$.

Rappaport, J. (1981). In praise of paradox: A social policy of empowerment over prevention. American Journal of Community Psychology, 9, 1-25.

Rappaport, J. (1984). Studies in empowerment: Introduction to the issue. Prevention in Human Services, 3, 1-7.

Rappaport, J. (1987). Terms of empowerment/exemplars of prevention: Toward a theory for community psychology. American Journal of Community Psychology, 15, 121-148.

Rappaport, J. (1990). Research methods and the empowerment social agenda. In P. Tolan, C. Keys, F. Chertok, \& L. Jason (Eds.), Researching community psychology: Integrating theories and methodologies (pp. 51-63). Washington, DC: American Psychological Association.

Rappaport, J., Reischl, T. M., \& Zimmerman, M. A. (1991). Mutual help mechanisms in the empowerment of former mental patients. In D. Saleebey (Ed.), The strengths perspective in social work practice: Power in the people. White Plains, NY: Longman.

Rich, R. C., Edelstein, M., Hallman, W. K., \& Wandersman, A. H. (1995). Citizen participation and empowerment: The case of local environmental hazards. American Journal of Community Psychology, 23, 657-676.

Roesch, R., \& Golding, S. L. (1980). Competency to stand trial. Urbana: University of Illinois Press.

Stone, R. A., \& Levine, A. G. (1985). Reactions to collective stress: Correlates of active citizen participation. Prevention in Human Services, 4, 153-177.

Strecher, V. T., DeVellis, B. M., Becker, M. H., \& Rosenstock, I. M. (1986). The role of self-efficacy in achieving health behavior change. Health Education Quarterly, 13, 73-92.

Sue, S., \& Zane, N. (1980). Learned helplessness theory and community psychology. In M. S. Gibbs, J. R. Lachenmeyer, \& J. Sigal (Eds.), Community Psychology: Theoretical and empirical approaches (pp. 121-143), New York: Gardner.

Whyte, W. F. (1991). Participatory action research. Newbury Park, CA: Sage.

Yeich, S., \& Levine, R. (1992). Participatory research's contribution to a conceptualization of empowerment. Journal of Applied Social Psychology, 22, 1894-1908.

Zimmerman, M. A. (1990a). Taking aim on empowerment research: On the distinction between psychological and individual conceptions. American Journal of Community Psychology, 18, 169-177.

Zimmerman, M. A. (1990b). Toward a theory of learned hopefulness: A structural model analysis of participation and empowerment. Journal of Research in Personality, 24, 71-86.

Zimmerman, M. A. (in press). Empowerment theory: Psychological, organizational and community levels of analysis. In J. Rappaport \& E. Seidman (Eds.), The handbook of community psychology. New York: Plenum Press.

Zimmerman, M. A., Israel, B. A., Schulz, A., \& Checkoway, B. (1992). Further explorations in empowerment theory: An empirical analysis of psychological empowerment. American Journal of Community Psychology, 20, 707-727. 
Zimmerman, M. A., Ramirez, J., Suarez, E., de la Rosa, G., \& Castro, M. A. (1994). Empowering processes: An example from an HIVIAIDS prevention project for Mexican homosexual men. Paper presented at the annual meeting of the American Public Health Association, Washington, DC.

Zimmerman, M. A., \& Rappaport, J. (1988). Citizen participation, perceived control, and psychological empowerment. American Journal of Community Psychology, 16, 725-750.

Zimmerman, M. A., \& Zahniser, J. H. (1991). Refinements of sphere-specific measures of perceived control: Development of a socio-political control scale. Journal of Community Psychology, 19, 189-204. 